\title{
Non Invasive Diagnosis to Predict Adynamic Bone Disease in Haemodialysed Patients
}

\author{
Yasser Soliman , Ahmed R. Aly , Sahar M. Shawky \\ Internal Medicine Department, Nephrology Unit Faculty of Medicine \\ Ain Shams University
}

\begin{abstract}
Precise evaluation of the underlying type of bone disease in hemodialysed patients frequently requires bone histomorphometry (including static and kinetic variables after double tetracycline labeling) which is an invasive and costly method. Due to the prevalence of adynamic bone disease in hemodialysis patients, different biochemical non invasive markers such as (serum intact osteocalcin, serum intact parathyroid hormone (iPTH) and bone specific alkaline phosphatase (bAP) have been shown to be helpful in differentiation between low and high bone turnover.

Our study was conducted to detect the usefulness of measuring serum intact osteocalcin and its correlation with serum iPTH and bAP to distinguish adynamic bone disease from other forms of renal osteodystrophy in hemodialysed patients.

The study included 60 patients and 20 normal control subjects, presented at renal dialysis units, Ain Shams University hospitals.

The hemodialysed patients were classified according to the results serum iPTH and bAP into two groups :

- Group I : $\quad$ Included 18 patients (30\%) with serum iPTH level $\leq 150 \mathrm{pg} / \mathrm{ml}$ and serum $\mathrm{bAP} \leq 27 \mathrm{ng} / \mathrm{ml}$.

- Group II : Included 42 patients (70\%) with serum iPTH level $>150 \mathrm{pg} / \mathrm{ml}$ and serum bAP $>27 \mathrm{ng} / \mathrm{ml}$.

The serum level of intact osteocalcin was measured for the control group and for all hemodialysed patients.

The results revealed highly significant stastical differences in serum level of intact osteocalcin between all patients group and the control subjects being lower in control group.

Also, the results revelaed that $30 \%$ of all patients group had adynamic bone disease and comparison between serum level of intact osteocalcin in adynamic bone disease group versus other patients group was highly significant, being higher in other patients group.

There was no significant difference between adynamic bone disease patients and other patients as regard serum phosphorus, and serum calcium but there was a sigificant difference as regard age, while highly significant difference as regard sex, duration of hemodialysis, serum intact osteocalin, iPTH and bAP.

These results suggest that combined estimation of serum iPTH, serum intact osteocalcin, and bAP can provide a useful information on the bone status in uremic patients and repesent reliable non invasive diagnostic tools for the prediction of adynamic bone disease.
\end{abstract}

\section{Introduction}

Chronic renal failure is often associated either with increased bone resorption such as, secondary hyperparathyroidism, osteoporosis, mixed bone disease, B2-microglobulin osteo-arthropathy (Gagné et al., 1992), or with decre- ased bone remodeling such as aluminum related low bone turnover,adynamic bone osteopathy (Goodman et al., 1999).

The prevalence of adynamic bone disease in dialysis patients has probably increased during the last decade, reaching a 
proportion varying between 15 and $60 \%$ of patients. This wide range can probably be attributed to a number of factors including, varying patient selection criteria, differences in prescription of aluminum versus calcium-based phosphate binders, inappropriate treatment of tap water, and variable usage of vitamin D metabolities (Hercz et al., 1993).

Although, bone histomorphometry is the most reliable diagnostic method, several new biochemical markers of bone turnover have been proposed in recent years for the evaluation of bone remodeling in uremic patients.However, in many cases, clinical and laboratory techniques could be used to avoid this invasive procedure, which can only be performed in specialized centres.

Recently, it was suggested that markers of bone turnover such as iPTH, bone alkaline phosphatase (bAP) were unable to distinguish among low- turnover bone disease, normal bone, and mild osteitis fibrosa (Qi et al., 1995).

In the cases of high plasma bone alkaline phosphatase associated with low or within the limits plasma intact PTH was explained by extraskeletal synthesis of bone alkaline phosphatase, either hepatic or renal as the liver, kidney, and bone alkaline phosphatase isoenzymes are encoded by the same gene (Whyte et al., 1995). Also, the production of skeletal bone alkaline phosphatase could be independent of the production of PTH- stimulated osteoblastic activity, as several cytokines and growth factors (IL-I, IL-6 and TNF) have been shown to exert a parathyroid hormone like action on bone cells (Hruska and Terrelbaum, 1995).

On contrast, the finding of low plasma bone alkaline phosphatase concentration with high plasma intact PTH levels probably reflects reduced bone alkaline phosphatase synthesis by uremic osteoblasts as cultured osteoblasts from hemodialysis patients respond less well to PTH than those from normal individuals (Fedde et al., 1996). The poor response of osteoblasts to PTH and the low plasma bone alkaline phosphatase may result from down-regulation of PTH receptors in these uremic cells (Ureña et al., 1996).

Also, the interpretation and significance of iPTH level in the individual patient is further complicated by skeletal resistance to $\mathrm{PTH}$ in chronic renal failure (Lepage et al., 1998) and plasma iPTH doesnot provide sufficient information as it basically reflects the parathyroid gland activity (Maraganella et al., 2002).

Therefore, additional tests or new markers of bone remodeling are needed that allow a correct and dynamic non invasive diagnosis of bone turnover, and have to be compared and/or combined with iPTH plasma values.

Based on previous literatures and histological studies which were done by (Couttenye et al., 1996) who showed that when both serum level of bone specific alkaline phosphatase was $\leq 27 \mathrm{ng} / \mathrm{ml}$ and serum iPTH level $\leq 150 \mathrm{pg} / \mathrm{ml}$, the specificity for the diagnosis of adynamic bone disease was increased to $91.5 \%$. Ferreira (1998) found that when bone specific alkaline phosphatase $\leq 27 \mathrm{ng} / \mathrm{ml}$ were associated with serum iPTH $\leq 150$ $\mathrm{pg} / \mathrm{ml}$, the positive predictive value for the diagnosis of adynamic bone disease increased from $84 \%$ to $94 \%$. While Ureña et al. (1996) showed that serum level of bone specific alkaline phosphatase > 27 $\mathrm{ng} / \mathrm{ml}$ had a sensitivity of $100 \%$ and specificity of $100 \%$ for the diagnosis of high turnover bone disease.

Tetsuo et al. (2000)found that intact osteocalcin could distinguish adynamic bone disease from mild lesion renal osteodystrophy, and diagnostic performance of serum intact osteocalcin as a diagnostic analyte at different cut-off values revealed that $<30-37 \mathrm{ng} / \mathrm{ml}$, patients were more likely to have adynamic bone disease.

Osteocalcin or bone Gla-Protein is a vitamin $\mathrm{K}$ dependent protein secreted from osteoblasts and increased in renal failure due to retention, Its levels increase with age after 45 years in both sexes, linearly in males and expotentially in females (Del Pino et al., 1990).

This peptide has been found to have selective binding affinity for insoluble $\mathrm{Ca}++$ 
salts, especially hydroxyapatite crystals of bone, it plays an important role in the mineralization of osteoid matrix (Boskey et al., 1998). Serum osteocalcin concentration has been reported to correlate with some parameters of bone resorption and is the most important predictor of indices of mineralization and bone formation in uremic patients (Koshihara and Hoshi, 1997).

\section{Aim of the Work}

To apply reliable non invasive tools to asses the usefulness of measuring serum intact osteocalcin, serum iPTH, and serum $\mathrm{bAP}$ in diagnosis of adynamic bone disease among hemodialysed patients.

\section{Subjects and Methods}

This study was carried out on 60 patients with chronic renal failure randomly selected from renal dialysis units, Ain Shams University Hospitals. All were on regular hemodialysis more than 1 year and recieving 3 sessions of hemodialysis weekly, 4 hours each, calcium concentrate in the dialysate was $3 \mathrm{~m} . E q L$. Their ages ranged from 27 to 72 years with a mean value of $44.97 \pm 16.9$.

Thirty - two were males and 28 were females with a male to female ratio of 1.14:1. All patients were receiving one alpha hydroxy vitamin D3 $0.25 \square \mathrm{g}$ daily which was discontinued at least 4 weeks before the study, and calcium acetate $3 \mathrm{gm} /$ day. Reverse osmosis systems and water softeness were used in dailysis units. Twenty age and sex matched healthy volunteers were enrolled in the present study as control, 8 were males and 12 were females with male: female ratio of 1:1.5. Control subjects were judged normal after a physical examination, as well as standard hematological and biochemical evaluations.

Patients with parathyroidectomy, diabetes mellitus, history of certain drug intake as corticosteroids, anticonvulsants, aluminum containling phosphate binders were excluded from the study.
All the patients and controls were subjected to the following:

A- Detailed history and thorough clinical examination.

B- Laboratory investigation that included : blood urea, serum creatinine, serum corrected calcium, serum phosphorus, serum bAP, serum iPTH and serum intact osteocalcin levels. In dialysis patients, blood samples were obtained before starting the dialysis session.

C- X-ray studies of hands and/or hips.

D- Measurement of Selected bone markers:

\section{1- Serum Parathyroid Hormone:}

Serum levels of parathyroid hormone was measured by immunoen-zymetic assay for the quantitative measurement of iPTH. Serun samples should be promptly separated from blood cells and temporarly kept on ice or refrigerated at $4^{\circ} \mathrm{C}$. If test is not run within 8 hours, store the samples at $20{ }^{\circ} \mathrm{C}$. 2 freezing - thawing cycles are allowed.

PTH-enzyme-linked immunosorbent assay (ELISA), is solid phase enzyme amplified sensitivity performed on microtiter plate .

It allows the determination of $\mathrm{PTH}$ in serum or plasma standard or samples bind to the affinity chromatography purified antibodies (Pabs, goat, anti 1-34 PTH fragment) coated on the inner surface of the microwell.

Intra-and inter assay variations were 6.5 and $9.8 \%$, respectively. Normal mean value is $29.80 \pm 7.43 \mathrm{pg} / \mathrm{ml}$ (range 10-71 $\mathrm{pg} / \mathrm{ml}$ ).

\section{2- Serum osteocalcin:}

Serum levels of intact osteocalcin or GLa was measured by an immunoenzymetic assay for the quantitative measurement of intact human osteocalcin (host) in serum and plasma and should not measure osteocalcin fragments.

The osteocalcin ELISA is a solid phase enzyme amplified sensitivity immunoassay (EASIA) performed on a microtiter plate. The assay uses monoclonal antibodies (MAbs) directed against the 
distinct epitopes of human osteocalcin. The blood samples were collected predialysis early in the morning. Serum was separated and stored at $-70^{\circ} \mathrm{C}$ until measurement. The intra-and inter assay variations were less than 5 and $8 \%$ respectively normal mean value $5.89 \pm 1.45 \mathrm{ng} / \mathrm{ml}$.

\section{3- serum bone specific alkaline phosphatase .}

The serum specimens should be collected without anticoagulants to avoid hemolysis. bAP immunoassay by ALK phase-B utilizing a monoclonal anti-bone alkaline phosphatase antibody coated on the strip to capture bone alkaline phos-phatase in the sample. ALK phase-B expe-cted values varied according to sex and age

Females $\{25-55$ years and $>55$ were 11.6-30.6 $\square / \mathrm{L}$ (median 18.7) and 14.8 $43.4 \square / \mathrm{L}$ (median 25.8) respectively\} while in males $\geq 25$ years was $15.0-41.3 \square / \mathrm{L}$ (median 23.2).

Stastical analysis was performed on IBM- Compatible PC by using SPSS 8.0 stastical software under windows 98 operating system. Graphic presentation of data was perforned by using office 200 Excel software .

Stastical evaluation was performed expressed as mean \pm Standard deviation followed by student t-test analysis. Correlations between 2 variables were estimated by using mann Whitney U-test (zvalue).

Diagnostic performance of serum osteocalcin was performed by calculation of its diagnostic accuracy at different cut-off values.

A p-value $<0.05$ was considered stastically significant (Altman, 1994).

\section{Results}

Results of the present study were described in tables (1-8) and figures (1-5). Tables from 1-5 express the descriptive statistics of all studied parameters in concurrence with analytical comparisons between studied groups. Tables (6-7) express the results of the correlation analysis between serum intact osteocalcin and other studied parameters in group I and group II.
Table (8) expressest the diagnostic performance of serum intact osteocalcin.

The optimal cut-off levels for the diagnosis of adynamic bone disease were determined, being $\leq 27 \mathrm{ng} / \mathrm{ml}$ for bone alkaline phosphates (bAP), and $\leq 150 \mathrm{pg} / \mathrm{ml}$ for serum $\mathrm{iPTH}$ (Couttenye et al., 1996) (Ferreira, 1998).

According to the diagnostic performance of serum intact osteocalcin (table 8), the optimal cut-off level of serum intact osteocalcin $<33-37 \mathrm{ng} / \mathrm{ml}$ for the diagnosis of adynamic bone disease.

So, according to these parameters, 18 patients out of 60 patients $(30 \%)$ were diagnosed having adynamic bone disease (group I) and the others 42 patients out of 60 patients $(70 \%)$ as group II.

Showed non significant difference $(\mathrm{P}>$ 0.05 ) between control group versus all patients group with age, serum calcium and serum bone specific alkaline phosphatase. While highly significant difference $(\mathrm{P}<0.01)$ with serum phosphorus, serum intact $\mathrm{PTH}$, serum creatinine and serum intact osteocalcin.

Showed non significant differences $(\mathrm{P}>0.05)$ between control group versus other patients group (Group II) with age and serum calcium. While highly significant differences $\quad(\mathrm{P}<0.01) \quad$ with serum phosphorus, serum bone specific alkaline phosphatase, serum intact PTH, serum intact osteocalcin and serum creatinine.

Showed non significant differences $(\mathrm{P}>0.05)$ between adynamic bone disease (Group I) and other patients groups (Group II) with serum phosphorus, serum calcium and serum creatinine. While significant differences $(\mathrm{P}<0.05)$ with age and highly significant difference $(\mathrm{P}<0.01)$ with duration of hemodialysis, serum bone specific alkaline phosphatase, serum intact PTH and serum intact osteocalcin.

Showed non significant difference $(\mathrm{P}>0.05)$ between control group versus all patients and between control group versus other patients group as regard sex. While significant difference between control group versus adynamic bone disease and highly significant difference between adynamic 
bone disease (Group I) and other patients group (Group II).

Showed non significant correlation $(\mathrm{P}>0.05)$ between serum intact osteocalcin with serum calcium, serum phosphorus and serum creatinine while significant correlation $(\mathrm{P}<0.05)$ with age and highly significant correlation $(\mathrm{P}<0.01)$ with duration of hemodialysis and serum bone specific alkaline phosphatase and serum intact PTH in adynamic bone disease patients (Group I).
Showed non significant correlation $(\mathrm{P}>0.05)$ between serum intact osteocalcin with age, serum calcium, serum bone specific alkaline phosphatase and serum intact PTH. while significant correlation $(\mathrm{P}<0.05)$ with S.Creatinine and highly significont correlation $(\mathrm{P}<0.01)$ with duration of hemodiolysis and serum phosphorus in the other patients group (group II). Table (1): Descriptive Stastics and Comparison of the mean variable in control group
versus all patients group

\begin{tabular}{|c|c|c|c|c|c|c|c|c|}
\hline \multirow{2}{*}{ Varibale } & \multicolumn{3}{|c|}{ Control group } & \multicolumn{3}{c|}{ All patients group } & \multirow{2}{*}{ Z } & \multirow{2}{*}{ P } \\
\cline { 2 - 7 } & $\mathbf{N}$ & Mean & \pm SD & $\mathbf{N}$ & Mean & \pm SD & & \\
\hline Age ( years) & 20 & 41.4 & \pm 14.45 & 60 & 44.97 & \pm 16.9 & -.915 & $>0.05$ \\
\hline Serum calcium mg/dl & 20 & 9.68 & \pm .595 & 60 & 9.49 & \pm .62 & 1.25 & $>0.05$ \\
\hline Serum phosphorus mg/dl & 20 & 3.58 & \pm .61 & 60 & 6.71 & \pm .90 & $-4.47^{* *}$ & $<0.01$ \\
\hline $\begin{array}{c}\text { Serum bone specific } \\
\text { alkaline phosphatase } \\
\text { ng/ml }\end{array}$ & 20 & 40.6 & \pm 11.33 & 60 & 44.23 & \pm 17.89 & -.851 & $>0.05$ \\
\hline $\begin{array}{c}\text { Serum intact PTH } \\
\text { pg/ml }\end{array}$ & 20 & 30 & \pm 4.05 & 60 & 274.83 & \pm 200.7 & $-5.43^{* *}$ & $<0.01$ \\
\hline $\begin{array}{c}\text { Serum intact osteocalcin } \\
\text { ng/ml }\end{array}$ & 20 & 4.30 & \pm 2.05 & 60 & 200.47 & \pm 239.06 & $-3.65^{* *}$ & $<0.01$ \\
\hline Serum creatinine mg/dl & 20 & .970 & \pm .264 & 60 & 9.86 & \pm 2.80 & $-14.11^{* *}$ & $<0.01$ \\
\hline
\end{tabular}

* sig $\quad * *$ Highly sig

Table ( 2): Descriptive Stastics and Comparison of the mean variable in control group versus Adynamic bone disease (Group I )

\begin{tabular}{|c|c|c|c|c|c|c|c|c|}
\hline Varibale & \multicolumn{3}{|c|}{ Control group } & \multicolumn{3}{c|}{ Adynamic bon disease } & \multirow{2}{*}{ Z } & \multirow{2}{*}{ P } \\
\hline & $\mathbf{N}$ & Mean & \pm SD & N & Mean & \pm SD & & \\
\hline Age ( years) & 20 & 41.4 & \pm 14.45 & 18 & 52.11 & \pm 17.49 & $-2.05^{*}$ & $<0.05$ \\
\hline Serum calcium mg/dl & 20 & 9.68 & \pm .595 & 18 & 9.24 & .71 & $2.03^{*}$ & $<0.05$ \\
\hline $\begin{array}{c}\text { Serum phosphorus } \\
\text { mg/dl }\end{array}$ & 20 & 3.58 & \pm .61 & 18 & 6.93 & \pm .96 & $-12.65^{* *}$ & $<0.01$ \\
\hline $\begin{array}{c}\text { Serum bone specific } \\
\text { alkaline phosphatase } \\
\text { ng/ml }\end{array}$ & 20 & 40.6 & \pm 11.33 & 18 & 23.44 & \pm 2.01 & $6.66^{* *}$ & $<0.01$ \\
\hline $\begin{array}{c}\text { Serum intact PTH } \\
\text { pg/ml }\end{array}$ & 20 & 30 & \pm 4.05 & 18 & 87.33 & \pm 46.87 & $-5.46^{* *}$ & $<0.01$ \\
\hline $\begin{array}{c}\text { Serum intact } \\
\text { osteocalcin }\end{array}$ & 20 & 4.30 & \pm 2.05 & 18 & 26.11 & \pm 16.55 & $-5.85^{* *}$ & $<0.01$ \\
\hline
\end{tabular}




\begin{tabular}{|c|c|c|c|c|c|c|c|c|}
\hline $\mathrm{ng} / \mathrm{ml}$ & & & & & & & & \\
\hline $\begin{array}{c}\text { Serum creatinine } \\
\mathrm{mg} / \mathrm{dl}\end{array}$ & 20 & .970 & \pm .264 & 18 & 9.29 & \pm 2.80 & $-13.3^{* *}$ & $<0.01$ \\
\hline
\end{tabular}

* sig **highly sig

Table (3): Descriptive Stastics and Comparison of the mean variable in control group versus Other patients (group II)

\begin{tabular}{|c|c|c|c|c|c|c|c|c|}
\hline Varibale & \multicolumn{3}{|c|}{ Control group } & \multicolumn{3}{c|}{ Other patients group } & \multirow{2}{*}{ Z } & \multirow{2}{*}{ P } \\
\hline Age ( years) & $\mathbf{N}$ & Mean & \pm SD & $\mathbf{N}$ & Mean & \pm SD & & \\
\hline Serum calcium mg/dl & 20 & 41.4 & \pm 14.45 & 42 & 41.91 & \pm 15.90 & -.124 & $>0.05$ \\
\hline Serum phosphorus mg/dl & 20 & 3.58 & \pm .61 & 42 & 6.61 & \pm .66 & $-15.87^{* *}$ & $<0.01$ \\
\hline $\begin{array}{c}\text { Serum bone specific } \\
\text { alkaline phosphatase } \\
\text { ng/ml }\end{array}$ & 20 & 40.6 & \pm 11.33 & 42 & 53.14 & \pm 13.71 & $-3.80^{* *}$ & $<0.01$ \\
\hline $\begin{array}{c}\text { Serum intact PTH } \\
\text { pg/ml }\end{array}$ & 20 & 30 & \pm 4.05 & 42 & 355.19 & \pm 187.1 & $-7.74^{* *}$ & $<0.01$ \\
\hline $\begin{array}{c}\text { Serum intact osteocalcin } \\
\text { ng/ml }\end{array}$ & 20 & 4.30 & \pm 2.05 & 42 & 275.19 & \pm 251.1 & $-4.80^{* *}$ & $<0.01$ \\
\hline Serum creatinine mg/dl & 20 & .970 & \pm .264 & 42 & 10.11 & \pm 2.80 & $-14.5^{* *}$ & $<0.01$ \\
\hline
\end{tabular}

* sig ** highly sig

Table(4): Descriptive Stastics and Comparison of the mean variable in Adynamic bone disease (Group I) versus other patients group ( Group II)

\begin{tabular}{|l|c|c|c|c|c|c|c|c|}
\hline \multicolumn{1}{|c|}{ Varibale } & \multicolumn{3}{c|}{ Adynamic bone disease } & \multicolumn{3}{c|}{ Other patients group } & \multirow{2}{*}{$\mathbf{Z}$} & \multirow{2}{*}{ P } \\
\cline { 1 - 6 } & $\mathbf{N}$ & Mean & \pm SD & $\mathbf{N}$ & Mean & \pm SD & & \\
\hline Age ( years) & 18 & 52.11 & \pm 17.49 & 42 & 41.91 & \pm 15.90 & $-2.13^{*}$ & $<0.05$ \\
\hline $\begin{array}{l}\text { Duratian of hemodialysis } \\
\text { (years) }\end{array}$ & 18 & 2.17 & \pm 1.16 & 42 & 4.69 & \pm 2.68 & $3.83^{* *}$ & $<0.01$ \\
\hline Serum calcium mg/dl & 18 & 9.24 & \pm .71 & 42 & 9.60 & \pm .55 & 1.85 & $>0.05$ \\
\hline Serum phosphorus mg/dl & 18 & 6.93 & \pm .96 & 42 & 6.61 & \pm .66 & -1.21 & $>0.05$ \\
\hline $\begin{array}{l}\text { Serum bone specific } \\
\text { alkaline phosphatase } \\
\text { ng/ml }\end{array}$ & 18 & 23.44 & \pm 2.01 & 42 & 53.14 & \pm 13.71 & $9.1 * *$ & $<0.01$ \\
\hline $\begin{array}{l}\text { Serum intact PTH } \\
\text { pg/ml }\end{array}$ & 18 & 87.33 & \pm 46.87 & 42 & 255.19 & \pm 187.1 & $-5.97 * *$ & $<0.01$ \\
\hline $\begin{array}{l}\text { Serum intact osteocalcin } \\
\text { ng/ml }\end{array}$ & 18 & 26.11 & \pm 16.55 & 42 & 275.19 & \pm 251.1 & $4.18^{* *}$ & $<0.01$ \\
\hline Serum creatinine mg/dl & 18 & 9.29 & \pm 2.80 & 42 & 10.11 & \pm 2.80 & 1.04 & $>0.05$ \\
\hline
\end{tabular}

* sig ** highly sig 
Table (5) : Descriptive statistics and various studied comparisons as regard sex

\begin{tabular}{|l|c|c|}
\hline & Male & Female \\
\hline Control group & 8 & 12 \\
All patients & 32 & 28 \\
Adymamic bone group & 16 & 2 \\
(Group I) & 16 & 26 \\
Other patients group & & \\
(Group II) & & \\
\hline
\end{tabular}

\begin{tabular}{|c|c|c|}
\hline & Chi squer test & p-value \\
\hline Control vs All patients & 1.07 & $>0.05(\mathrm{NS})$ \\
\hline $\begin{array}{l}\text { Control vs Adymamic bone disease } \\
\text { (Group I) }\end{array}$ & 9.731 & $<0.05(\mathrm{~S})$ \\
\hline $\begin{array}{l}\text { Control vs Other patients group (Group } \\
\text { II) }\end{array}$ & .021 & $>0.05(\mathrm{NS})$ \\
\hline $\begin{array}{l}\text { Adymamic bone disease vs Other patients } \\
\text { group }\end{array}$ & 13.061 & $<0.01(\mathrm{HS})$ \\
\hline
\end{tabular}

Table (6 ): Correlation of serum intact osteocalcin with various Parameters In adynamic bone disease patients group (Group I)

\begin{tabular}{|l|c|c|}
\hline \multicolumn{1}{|c|}{ Prameter } & R & p-value \\
\hline Age(years) & .565 & $<0.05(\mathrm{~S})$ \\
Duration(years) & .668 & $<0.01(\mathrm{HS})$ \\
Serum Calcium(mg/dl) & -.460 & $>0.05(\mathrm{NS})$ \\
Serum Phosphorus (mg/dl) & .565 & $<0.05(\mathrm{~S})$ \\
Serum Bone specific alkaline & .633 & $<0.01(\mathrm{HS})$ \\
phosphatase (u/l) & .639 & $<0.01(\mathrm{HS})$ \\
Serum intact PTH(pg/ml) & .401 & $>0.05(\mathrm{NS})$ \\
Serum Creatinine(mg/dl) & & \\
\hline
\end{tabular}

Table (7 ) : Correlation of serum intact osteocalcin with various Parameters In other patients group (Group II)

\begin{tabular}{|l|c|c|}
\hline \multicolumn{1}{|c|}{ Prameter } & R & p-value \\
\hline Age(years) & .01 & $>0.05(\mathrm{NS})$ \\
Duration(years) & $.559^{* *}$ & $<0.01(\mathrm{HS})$ \\
Serum Calcium(mg/dl) & .095 & $>0.05(\mathrm{NS})$ \\
Serum Phosphorus (mg/dl) & .617 & $<0.01(\mathrm{HS})$ \\
Serum Bone specific alkaline & .285 & $>0.05(\mathrm{NS})$ \\
phosphatase (u/l) & .209 & $>0.05(\mathrm{NS})$ \\
Serum intact PTH(pg/ml) & $.327^{*}$ & $<0.05(\mathrm{~S})$ \\
Serum Creatinine(mg/dl) & & \\
\hline
\end{tabular}


Non Invasive Diagnosis to Predict Adynamic Bone................

Table (8): Diagnostic performance of serum intact osteocalcin as a diagnostic analyte for differentiation between adynamic bone disease patients versus other patients at different cut-off values.

\begin{tabular}{|c|c|c|c|c|c|c|}
\hline Cut-of value & $\begin{array}{c}<15 \\
(\mathrm{ng} / \mathrm{ml})\end{array}$ & $\begin{array}{c}<16 \\
(\mathrm{ng} / \mathrm{ml})\end{array}$ & $\begin{array}{c}<17- \\
(\mathrm{ng} / \mathrm{ml})\end{array}$ & $\begin{array}{c}<19 \\
(\mathrm{ng} / \mathrm{ml})\end{array}$ & $\begin{array}{c}<20- \\
(\mathrm{ng} / \mathrm{ml})\end{array}$ & <29- $(\mathrm{ng} / \mathrm{ml})$ \\
\hline $\mathrm{TP}$ & 0 & 2 & 4 & 8 & 10 & 10 \\
\hline $\mathrm{TN}$ & 38 & 38 & 38 & 38 & 38 & 34 \\
\hline FP & 4 & 4 & 4 & 4 & 4 & 8 \\
\hline $\mathrm{FN}$ & 18 & 16 & 14 & 10 & 8 & 8 \\
\hline \multicolumn{7}{|c|}{ Diagnostic performance } \\
\hline Sensitivity & 0.00 & 11.1 & 22.2 & 444.4 & 55.6 & 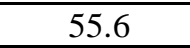 \\
\hline Specificity & 90.5 & 60.5 & 90.5 & 60.5 & 90.5 & 81.0 \\
\hline PPV & 0.00 & 33.3 & 50.0 & 66.7 & 71.4 & 55.6 \\
\hline NPV & 67.9 & 70.4 & 73.1 & 79.2 & 82.6 & 81.0 \\
\hline DA & 63.3 & 66.7 & 70.0 & 76.7 & 80.0 & 73.3 \\
\hline \multicolumn{7}{|c|}{ Likelihood ratio } \\
\hline LR+ve & 0.00 & 1.167 & 2.333 & 4.667 & 5.833 & 2.917 \\
\hline LR-ve & 1.105 & 0.982 & 0.860 & 0.614 & 0.491 & 0.549 \\
\hline \multicolumn{7}{|l|}{ Agreement : } \\
\hline $\mathrm{K}$ index & -0.12 & 0.020 & 0.151 & 0.386 & 0.492 & 0.365 \\
\hline Cut-off value & $\begin{array}{c}<31- \\
(\mathrm{ng} / \mathrm{ml})\end{array}$ & $\begin{array}{c}<33- \\
(\mathrm{ng} / \mathrm{ml})\end{array}$ & $\begin{array}{c}<38- \\
(\mathrm{ng} / \mathrm{ml})\end{array}$ & $\begin{array}{c}<43- \\
(\mathrm{ng} / \mathrm{ml})\end{array}$ & $\begin{array}{c}<65- \\
(\mathrm{ng} / \mathrm{ml})\end{array}$ & $<87(\mathrm{ng} / \mathrm{ml})$ \\
\hline $\mathrm{TP}$ & 14 & 16 & 16 & 16 & 16 & 18 \\
\hline $\mathrm{TN}$ & 34 & 34 & 32 & 30 & 28 & 28 \\
\hline FP & 8 & 8 & 10 & 12 & 14 & 14 \\
\hline FN & 4 & 2 & 2 & 2 & 2 & 0 \\
\hline \multicolumn{7}{|c|}{ Diagnostic performance: } \\
\hline Sensitivity & 77.8 & 88.9 & 88.9 & 88.9 & 88.9 & 100.0 \\
\hline Specificity & 91.0 & 81.0 & 76.2 & 71.4 & 66.7 & 66.7 \\
\hline PPV & 63.6 & 66.7 & 61.5 & 57.1 & 53.3 & 56.3 \\
\hline NPV & 89.5 & 94.4 & 94.1 & 93.8 & 93.3 & 100.0 \\
\hline DA & 80.0 & 83.3 & 80.0 & 76.7 & 73.3 & 76.7 \\
\hline \multicolumn{7}{|c|}{ Likelihood ratio } \\
\hline LR+ve & 4.083 & 4.667 & 3.733 & 3.11 & 2.667 & 3.000 \\
\hline LR-ve & 0.275 & 0.137 & 0.146 & 0.156 & 0.167 & 0.000 \\
\hline \multicolumn{7}{|l|}{ Agreement : } \\
\hline K. index & 0.552 & 0.638 & 0.577 & 0.521 & 0.521 & 0.545 \\
\hline
\end{tabular}


TP : (True positive).

FP : (False positive).

Sensitivity $=\mathrm{TP} /(\mathrm{TP}+\mathrm{FN})$.
TN: (True negative).

FN: (False negative).

Specificity $=\mathrm{TN} /(\mathrm{TN}+\mathrm{FP})$.

PPV : (Positive predictive value $)=\mathrm{TP} /(\mathrm{TP}+\mathrm{FP})$.

NPV : (Negative predictive value $)=T N /(T N+F N)$.

DA $:($ Diagnostic accuracy $)=(\mathrm{TP}+\mathrm{TN}) /$ total.

$\mathrm{LR}+\mathrm{ve}=$ Likelihood ratio positive test $=(\mathrm{TP} / \mathrm{TP}+\mathrm{FN}) /(\mathrm{FN} / \mathrm{FN}+\mathrm{TN})$.

$\mathrm{LR}-\mathrm{ve}=$ Likelihood ratio negative test $=(\mathrm{FN} / \mathrm{TP}+\mathrm{FN}) /(\mathrm{TN} / \mathrm{TN}+\mathrm{FP})$.

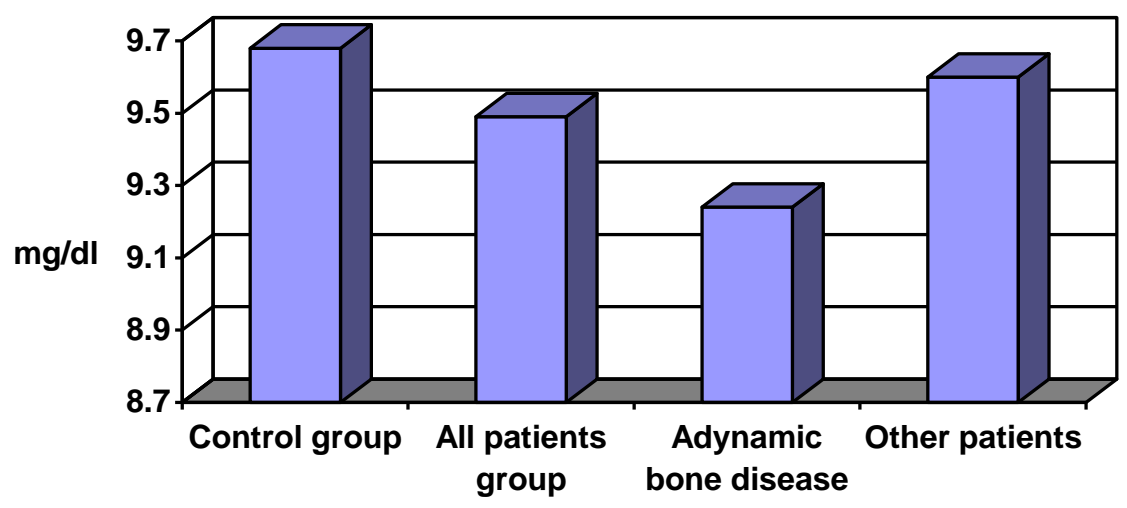

Fig(1): mean serum calcium in all studied groups

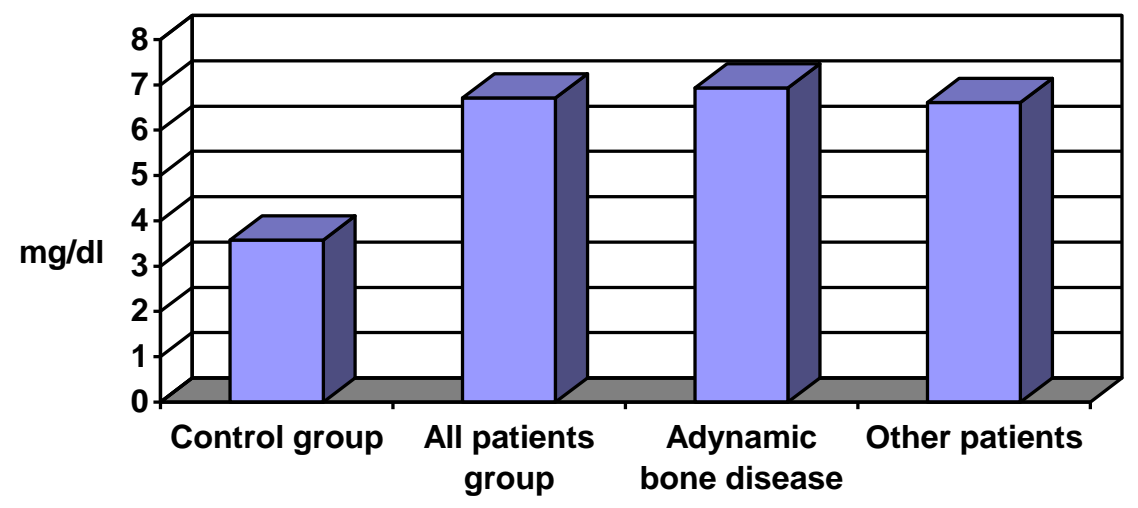

Fig(2): mean serum phosphorus in all studied groups 


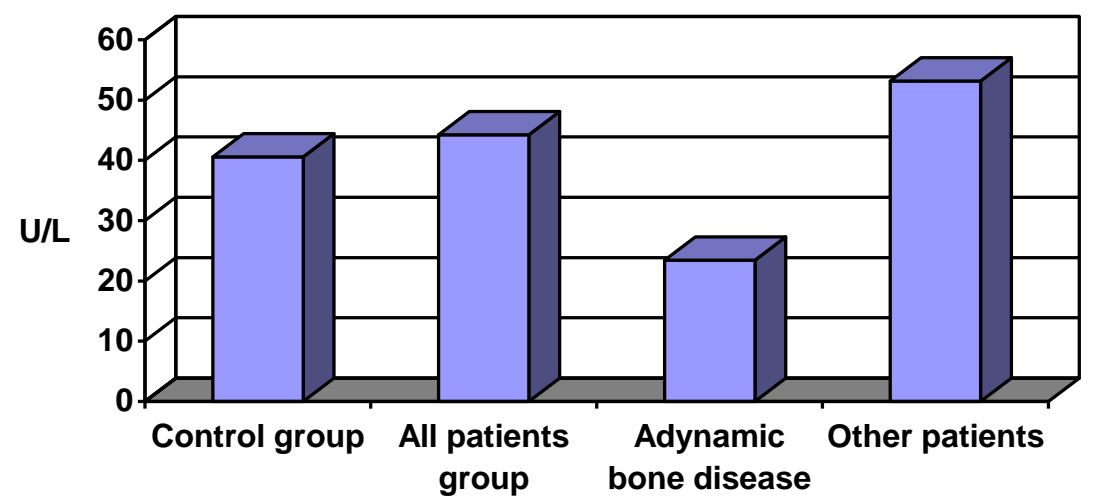

Fig(3): mean serum bone specific alkaline phosphatase in all studied groups

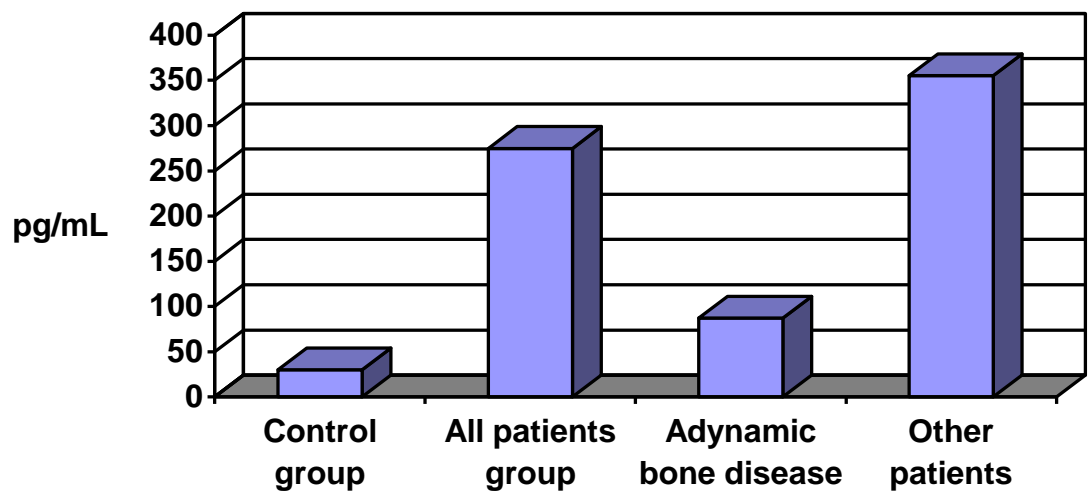

Fig(4): mean serum intact parathyroid hormone in all studied groups

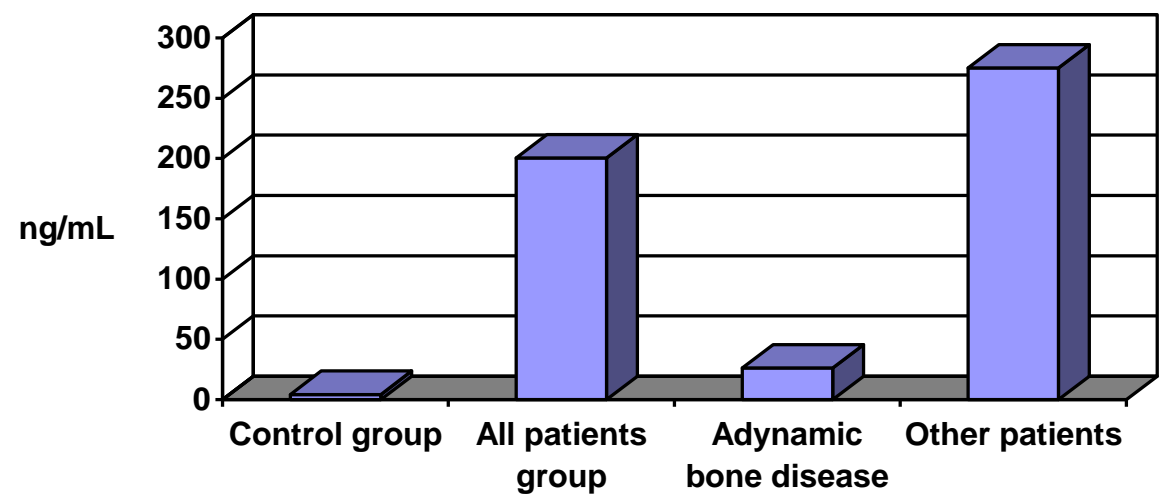

Fig (5): mean serum intact osteocalcin in all studied groups

\section{Discussion}

Bone is a dynamic tissue, which is continuously renovating in a process called remodeling. In pathological conditions, such as renal osteodystrophy, this process may be either accelerated or down regul-ated, so both high-and low- turnover renal 
osteopathies can be found (Giorgio et al., 2002).

Therapeutic regimens aimed to reduce parathyroid hormone secretion by administration of $1 \alpha, 25$ dihydroxyvitamin D3 on one hand, descreases the frequency and the severity of osteitis fibrosa, but on the other hand, it is continued to the pathogenesis of other forms of renal osteodystrophy as adynamic bone disease (Anca and Mordecai, 2002).

Our study showed that $30 \%$ of the studied patients had adynamic bone disease and this was in agreement with (Salusky and Goodman, 2001) who found that $40 \%$ of patients on hemodialysis had bone biopsy evidence of adynamic renal osteodystrophy.

Our study showed that the mean age of patients with adynamic bone disease was slightly higher than other patients $(52.11 \pm 17.49$ versus $41.91 \pm 15.90)$ (Table 4) and these results were in concordance with the previous study done by Couttenye et al. (1997) who found that adynamic bone disease was more common in older patients above sixty years.

Our study showed a significant difference between males and females in the prevalence of adynamic bone disease, 16 patients out of 18 with adynamic bone disease were males (Table 5). This may be due to the role of estrogen, which has an antiresorptive effect (Salusky and Goodman, 2001).

The study showed an inverse relation between the duration of hemodialysis and the prevalence of adynamic bone disease (Table 4) this may be explained by the bone response to PTH in renal failure increased after dialysis was initiated and the dialysis treatment might remove toxins responsible for the impaired bone response to PTH (Torres et al., 1995).

Our study proved that hyperphosphatemia was common in dialysis patients and could be associated with all pattern of renal osteodystrophy, so there was no significant difference between adynamic bone disease and others ( Table 4), ( Figure 2). Also there was no significant difference in the serum calcium between adynamic bone disease and other patients group (Table
4), ( Figure 1) so serum calcium and phosphorus cannot diffrantiate between different types of bone disease in hemodialysed patients and this was in concordance with Malluche et al., (1984).

A highly significant difference was found in serum bAP levels between group I and group II ( Table 4), ( Figure 3) being higher in group II patients and this agreed with Gouttenye et al. (1996), who found that low serum bAP excluded with a high degree of certainly $100 \%$ in studied population the presence of hyperparathyroid bone disease.

An additional advantage of serum bAP determination in renal failure patients is, its high molecular weight $(16 \mathrm{KDa})$ making its clearance independent of renal function, and due to the development of monoclonal antibodies specific for bone alkaline phosphatase provided the basis for a more specific index for bone formation (Hill and Wolfert, 1989).

Our study proved significant difference as regard serum iPTH between all groups ( Table 4), ( Figure 4) being the highest in group II, and this was in agreement with Ferreira, (2000) who found that iPTH could predict the type of bone histology. Also our study was in concordance with Couttenye et al. (1997) who found that low value of iPTH $<150$ $\mathrm{pg} / \mathrm{ml}$ had a sensitivity $80.6 \%$ and specificity $76.2 \%$ for the diagnosis of adynamic bone disease.

Osteocalcin was elevated in all patients included in this study ( Table 1), these results were in concordance with Solusky et al. (1994) who found that osteocalcin levels were higher in patients with renal osteodystrophy both in high and low turnover renal osteodytrophy but being above the normal range in patients with adynamic bone disease ( Table 2) and extremly elevated in patients with high bone turn over ( Table 3), ( Figure 5)

Our study showed that serum intact osteocalcin had significant correlations with, serum bAP in concordance with (Garnero and Delmas, 1998), serum $\mathrm{iPTH}$ in concordance with (Gerakis et al., 1996), and the duration of hemodialysis ( Table 6), 
but non significant negative correlation with serum $\mathrm{Ca}++$ (Table 6), in agreement with (Gundberg et al., 1985) because ionized serum calcium was responsible for the affinity of serum intact osteocalcin to hydroxyapatite, so changes in the serum calcium may alter adsorption of serum intact osteocalcin to hydroxyapatite and result in changes in serum intact osteocalcin levels.

Our study showed that, no significant positive correlation between serum intact osteocalcin and serum bAP and serum iPTH for the diagnosis of high bone turnover ( Table 7) and this clarrif-ied it as a useful bone marker when comb-ined with other bone markers as iPTH and serum bAP specially for the diagnosis of adynamic bone disease and not for the diagnosis of hyperparathyorid bone disease and this agreed with (Tetsuo et al., 2000).

The study showed that at serum intact osteocalcin cut-off value ranging from 33$37 \mathrm{ng} / \mathrm{ml}$, serum osteocalcin showed specificity of $81 \%$ and sensitivity of $88.9 \%$ for the diagnosis of adynamic bone disease with highest $\mathrm{K}$ index for agreement $\mathrm{K}$ index $=0.638($ Table 8$)$ and this agreed with Tetsuo et al. (2000) who found that at cutoff value of serum intact osteocalcin below $30 \mathrm{ng} / \mathrm{ml}$, the diagnostic specificity and sensitivity for adynamic bone disease were above $90 \%$, and in agreement with Coen et al. (1998) who found that serum intact osteocalcin with cut off value $36 \mathrm{ng} / \mathrm{ml}$ had sensitivity of $87.5 \%$ and specificity of $86 \%$ for the discrimination between low trunover and others. Also, our results showed that at cut-off value ranging between $33-37 \mathrm{ng} / \mathrm{ml}$ the positive predictive value was $66.7 \%$ and negative predictive value was $94.4 \%$ and this agreed with Couttenye et al. (1996) who found that at cut-off value $\leq 40 \mathrm{ng} / \mathrm{ml}$ had a positive predictive value of $55 \%$ and negative predictive value of $97 \%$.

\section{In conclusion}

Renal osteodystrophy is a frequent complication in hemodialysis patients and adynamic bone disease represents $30 \%$ of bone lesions, so, non invasive evaluation of bone turnover should include a combin-ation of different bone markers as (serum intact osteocalcin, serum iPTH, serum bAP), so that, the balance between bone formation and bone resorption can be assessed properly.

\section{References}

1. Altman DG (1994): Practical statistics for medical research. Chia bled champion and Hall, London: p 218.

2. Anca $G$ and Mordecai $M$ (2002): Parathyroid hormone independent osteocl-astic resorptive bone disease : A new variant of adynamic bone disease in haemodialysis patients. Nephrol Dial Transplant (suppl 17):620-624.

3. Boskey A, Gadaleta S, Gundberg C, et al. (1998): Fourier transform infrared microspectroscopic analysis of bones of osteocalcin deficient mice provides insight into the function of osteocalcin. Bone, 23:187-196.

4. Coen G, Ballanti C, Bonuccil E, et al. (1998): Bone markers in the diagnosis of low turnover osteodystrophy in haemod-ialysis patients. Nephrology Dialysis Tran-splantation, Vol 13, Issue 9:2294-2302.

5. Couttenye M, D'Haese P, Vanhoof V, et al. (1996): Low serum levels of alkaline phosphatase of bone origin : A good marker of adynamic bone disease in haemodialysis patients. Nephrol Dial Transplant, 11:1065-1072.

6. Couttenye M, D'Haese $\mathbf{P}$, Deng $\mathbf{J}$, et al. (1997) : High prevalence of adynomic bone disease diagnosed by biachemical markers in a wide Sample of the European CAPD papulation. Nephrol Dial Transplant, 12: 2144-2150

7. Gerakis A,Hutchison AJ, Apostolou TH, et al. (1996): Biochemical markers for noninvasive diagnosis of hyperparathyroid bone disease on hemodialysis. Nephrol Dial Transplant, 11:2430-8 
8. Del Pino J, Martin-Gomez E, Martin-Rodringuez $M$, et al. (1990): Influence of sex, age and menopause on serum osteocalcin (BGP) : Klin-wochenchr, 69(24):1135-8.

9. Fedde K, Michell M, Henthorn P, et al. (1996): Aberrant properties of alkaline phosphatase in patient correlate with clinical expressivity in severe forms of hypophosphtasia .J Clin Endocrinol Metab, 81:2587-2594.

10. Ferreira A (1998): Biochemical marker of bone turnover in the diagnosis of renal osteodystrophy : What do we have, what we need?. Nephrology dialysis transplant, 13 (suppl. 3) p. 29-32.

11. Ferreira A (2000) : Diagnosis of renal osteodystrophy : When and how to use biochemical markers and non invasive methods; when bone biopsy is needed. Nephrol Dial Transplant, 15(suppl 5):814.

12. Gagnē ER, Ureña P, Leite-Silva S, et al. (1992): Short and long term efficacity of total parathryoidectomy with immediate autografting compared with subtotal parathyroidectomy in hemodialysis patients. J Am Soc Nephrol, 3:1008-1017.

13. Garnero $P$ and Delmas $P$ (1998): New dev-elopment in chemical markers of osteopo-rosis. Calcif Tissue Int, 59(suppl) 1:2-9.

14. Giorgio C, Paola B, Alessandro B, et al. (2002): Serum osteoprotegerin and renal osteodystrophy. Nephrol Dial Transplant, 17:233-238.

15. Goodman WG, Coburn JW, Slatopolsky E, et al. (1999): Renal osteodystrophy in adults and children. In : Prime on the metabolic Bone diseases and disorders of mineral metabolism, 4th ed., edite by Favus MJ, philadelphia, Lippincott Williams and Wilkins, p. 347363.

16. Gundberg CM, Morkowitz ME, Mizruchi M, et al. (1985): Osteocalcin in human serum : A circadian rhythm. J Clin
Endomcrinol Metab, (60):736739.

17. Hercz Gt, Pei Y, Greenwood C,et al. (1993): Aplastic osteodystrophy without aluninum:The role of "Suppressed " Parathyroid function. Kid Int, 44: 860-866.

18. Hill CS and Wolfert RL, (1989): The preparation of monoclonal antibodies which react preferenctially with human bone alkaline phosphatases and not liver alkaline phosphatase. Clin Chim Acta, 186:315-20.

19. Hruska $K$ and Terrelbaum $\mathbf{S}$ (1995): Renal osteodystrophy. N Engl J Med, 333:166-174.

20. Koshihara Y and Hoshi K (1997): Vitamin K2 enhances osteocalcin accumulation in the extracellular matrix of human osteo-blast in vitro. J Bone Miner Res, 12:431438.

21. Lepage R, Roy L, Brossard J, et al. (1998): A non (1-84) Circulating parathyroid hormone (PTH) Fragment intereferes significantly with intact PTH commercial assay measurements in Uraemic Samples. Clin chem,44:805-809

22. Malluche HH, Faugere M, Fanti P, et al. (1984): plasma levels of bone- Gla- protein reflect bone formation in patients on chronic maintenance dialysis. Kid international, 27: 869-874.

23. Maraganella $\mathbf{M}$, Migliardi $\mathbf{M}$, Dutto. F, et al. (2002): Assessement of parathyroid function and bone turnover in dialysis patients. Congress of the ERA , EDTA. Copenhagen, Denmork, july Abst book, 0103P. 31.

24. Qi Q, Maunier-Faugere MC, Geng Z, et al. (1995): Predictive value of serum para-thyroid hormone levels for bone turnover in patients on chronic maintenance dialysis. Am J Kidney Dis, 26:622-31.

25. Salusky IB and Goodman WG (2001): Adynamic renal osteodystrophy : is there a problem? J Am Soc Nephrol, 12:1978-1985. 
26. Salusky IB, Ramirez J, and Goodman W. (1994): Disorders of bone and mineral metabolism in chronic renal failure. Holliday. A., Barratt T.M. and Avner E.D. (eds.) In : Paediatric nephrology., 3rd edition. Baltimore : A waverly Co.; 1288-305.

27. Tetsuo M, Masanori N, Masato H, et al. (2000) : A new assay method that detects only intact osteocalcin. Two step non invasive diagnosis to predict adynamic bone disease in haemodialysed patients. Nephrol Dial Transplant, 15:659-667.

28. Torres A, Lorenzo V, Harnades D, et al. (1995): Bone disease in predialysis, hemodialysis and CAPD patients : evidence of a better response to PTH. Kidney Int, 47:1434-1442.
29. Urĕna P Ferreira A Moreieux C, et al. (1996): $\mathrm{PTH} / \mathrm{THrP}$ receptor mRNA is down regulated in eiphyseal cartilage growth plate of uraemic rats. Nephrol Dial Transplant, 11:2008-16.

30. Ureña P, Hruby M, Ferreira A, et al. (1996) : Plasma total versus bone alkaline phosphatase as markers of bone turnover in hemodialysis patients. J Am Soc Nephrol, 7:1-7.

31. Whyte M, Landt M, Ryan L, et al. (1995): Alkaline phosphatase: Placental and tissue nonspecific isoenzymes hydrolyze phosphoethanolamine, inorganic pyrophosphate, and pyridoxal 5 phosphate. J Clin Invest, 95:1440-1445.

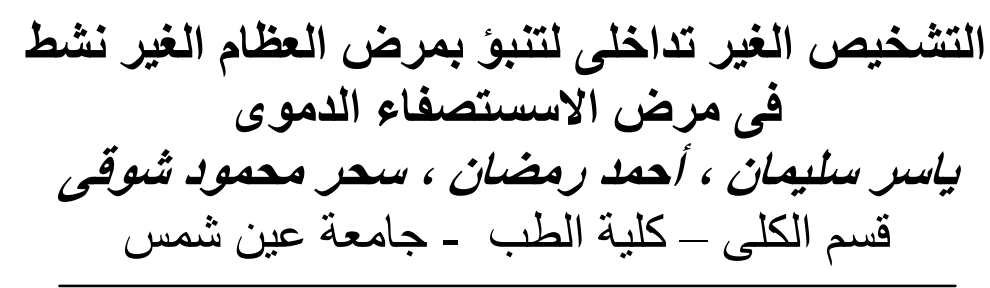

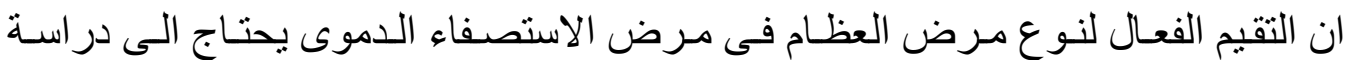

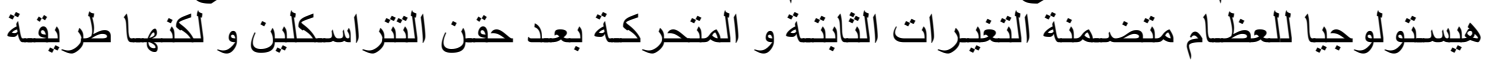

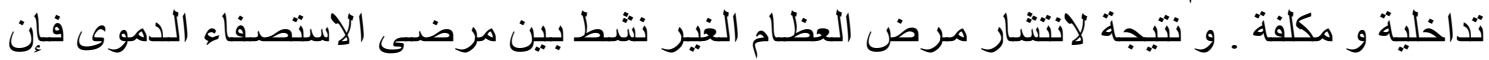

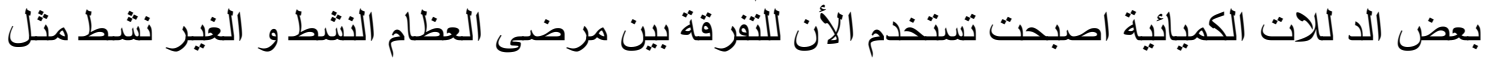
الاوستيوكالسين و هرمون الغدة الجار درقية ـ إن الهدف من الدراسة هو تقيم كفاءة استخدام قياس الغئس 
الأوستيوكالسين فى المصل ومقارنتها بهرمون الغدة الجار درقية و الفوسفات القلوى للعظام للتفرقة

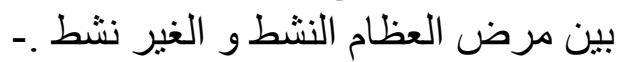
ـ قامت الدر اسة على 60 مريض و 20 شـخص غير فير مريض للمقارنـة وذ للك بوحدة الإستصفاء

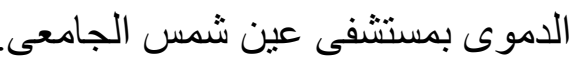

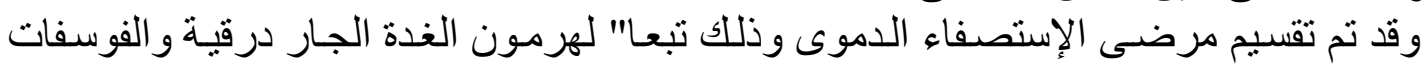
القلوى للعظام الى مجمو عتين:ـ المجموعة الأولى:تضى الفى 18 مريض( 30 \% \% ) وهرمون الغدة الجـار درقية فى مصل هؤلاء

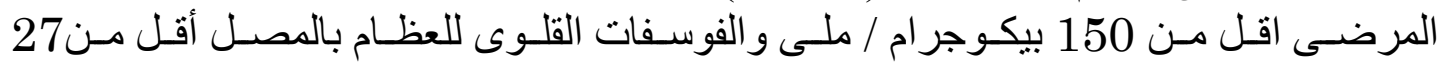
نانوجر ام/ ملى .

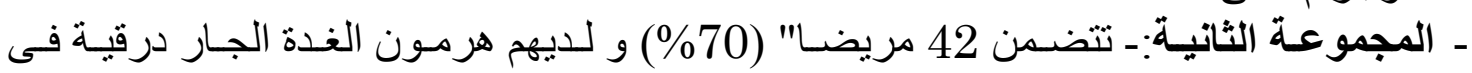

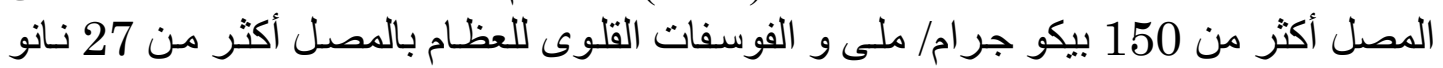

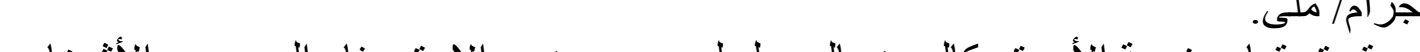

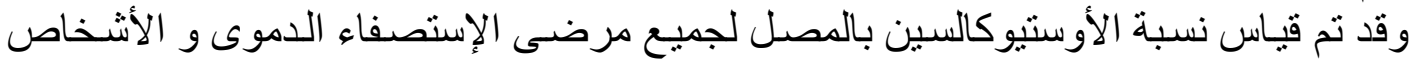

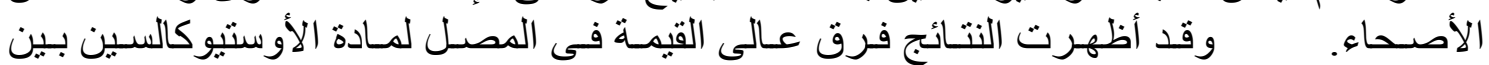

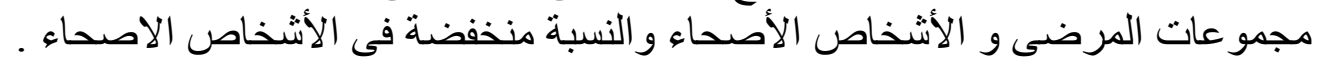

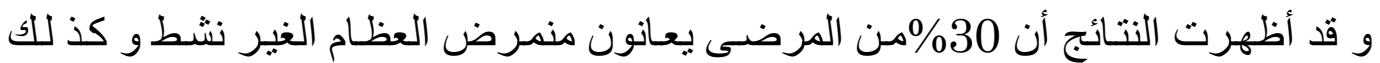

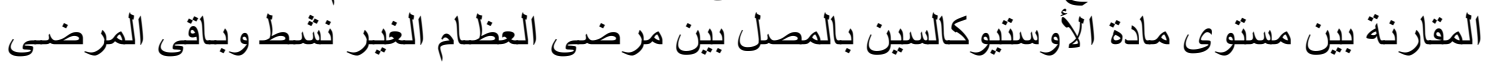

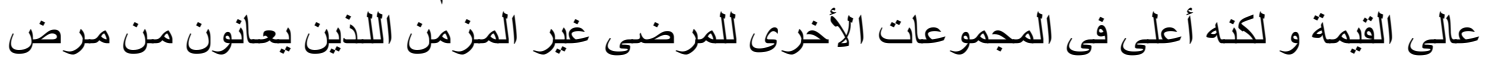

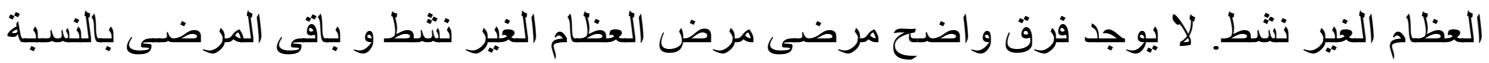

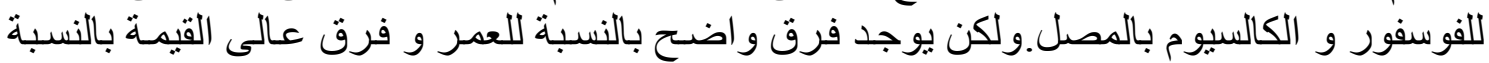

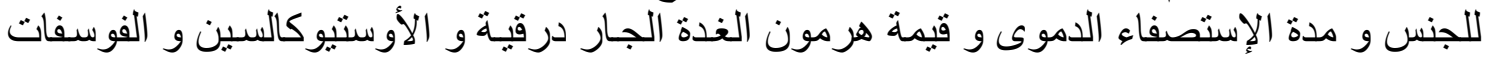

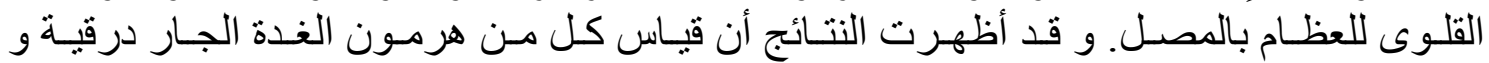

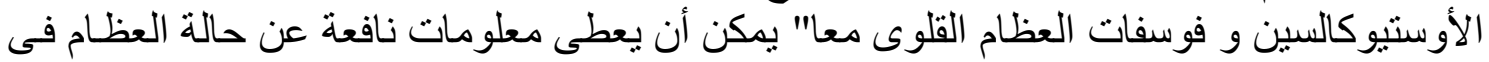
مرضى الإستصفاء الدموى وتمثل وسيلة غير تداخلية للتنبؤ بمرض العنى العظام الغير نشط. 